\title{
Development and Initial Validation of an Instrument to Measure Students' Learning about Systems Thinking: The Affective Domain
}

\author{
Fanny Camelia, Timothy L.J. Ferris, Senior Member, IEEE, David H. Cropley
}

\begin{abstract}
The purpose of this study was to develop and validate a new, theoretically-based scale that would assess students' learning about systems thinking in relation to the affective domain in systems engineering education. Students' learning of systems thinking in the affective domain deals with emotions, feelings and valuing the related cognitive systems thinking aspects. It is characterized by belief in the power of systems thinking to enable them to develop superior engineered products and systems. This paper describes the psychometric properties of the scale as the basis for future use with a target population of engineering students. It provides the results of an instrument test analysis of data collected from a representative set of the target audience of the instrument. The participants in this study were 180 undergraduate engineering students who enrolled in a systems engineering course. Exploratory factor analysis of the scale for the sample yielded factors largely consistent with conceptualization and construction of the subscales. Confirmatory factor analysis of the scale also supports the initial factor structure. The results suggest that this instrument may be useful to researchers and practitioners interested in measuring systems thinking in engineering students, particularly in the affective domain.
\end{abstract}

Index Terms-systems thinking, education, systems engineering, systems engineering education, systems engineering and theory, affective domain

\section{INTRODUCTION}

A $\mathrm{S}$ systems became more complex, dynamic, and interconnected, involving more stakeholders, and security and privacy issues, there was a corresponding need to implement Systems Engineering (SE) principles and practices $[1,2]$. This has led to a growth in demand for systems engineers and raised the importance of developing systems engineers. SE is recognized as a key discipline in a number of sectors including aerospace, defense, automotive, construction, energy, transportation, consumer electronics, IT, pharmaceuticals, healthcare and telecommunications [3].

In recent years, there has been an increased interest among government, industry and academia in identifying and developing SE education and training to support systems

Manuscript received XXX/XXX/XXXX. This work was supported by Indonesia Directorate General of Higher Education through DGHE $\mathrm{PhD}$ scholarship.

F. Camelia is with the Industrial Engineering Department, Ekasakti University, Padang, Indonesia, and with the School of Engineering, University of South Australia, Mawson Lakes, SA 5095 (e-mail: fanny.camelia@mymail.unisa.edu.au). engineering workforce development [4-8]. There has also been a rising interest in understanding systems thinking, one of the core competencies for SE $[9,10]$. This includes understanding systems thinking development and measurement as well as exploring new ways to leverage systems thinking $[9,10]$.

There is a limited systems thinking literature in engineering and SE. Development of systems thinking is poorly understood, especially within SE education and among SE undergraduate students. Little is known about how to develop systems thinking abilities in students [11], although some studies have been initiated to investigate systems thinking in the classroom in various grades and disciplines. This includes assessing systems thinking in primary school students [12], middle school students [13], undergraduate students in social sciences [14], undergraduate students in management [15], undergraduate students in sustainability [16] and graduate students in a modeling class [17]. However, most of these are based on cognitive perspectives. There is a lack of research about systems thinking development in relation to the affective domain perspective, which refers to Bloom's taxonomy of educational outcomes. This classifies learning into cognitive, affective and psychomotor domains [18]. Affective domain development deals with students' emotions, feelings and valuation of the cognitive domain aspects such as intellectual abilities and skills.

The lack of investigation of this subject, results in an absence of instruments capable of measuring the affective engagement with systems thinking. This paper explains the linkage of the affective domain perspective in systems engineering education and systems thinking. It reports the validation and reliability testing of a questionnaire to assess students' learning about systems thinking in the affective domain. This study is a prerequisite to the use of the questionnaire to measure the affective dimension of students' systems thinking as an outcome of an educational activity.

\section{Systems THINKING}

Systems thinking has become increasingly popular and

T.L.J. Ferris is with the Systems Engineering Centre, Cranfield University, Shrivenham, UK, SN8 6LA, and has an adjunct position with School of Engineering, University of South Australia, Mawson Lakes, SA 5095 (e-mail: timothy.ferris@cranfield.ac.uk).

D.H. Cropley is with the School of Engineering, University of South Australia, Mawson Lakes, SA 5095 (e-mail: david.cropley@unisa.edu.au). 
important because it provides a 'new way of thinking' to understand and manage complex problems [19-23]. The relevant literature is found in disparate fields, such as biology, psychology, health, education, engineering, and sustainability. It is not a central theme in any of these fields, but stimulates ongoing discussions within and between these fields as researchers investigate issues at the boundaries between them [24].

However, there is a disagreement about what systems thinking is [21]. It is interpreted in a variety of ways depending on discipline [25]. Some scholars view it as a science [26], others as a method [19] and yet others as an approach [27]. It is further viewed as a skill [17], a discipline [28], or a conceptual framework [20, 21, 29, 30]. The differences have led to limited application by policy makers, managers, practitioners, educators and ordinary people [20, 23, 31].

Systems thinking is neither a science nor a particular methodology nor an approach nor a plurality of methods, as many authors claim, but rather should be viewed as a mental construct for thinking and learning about a system [20, 21, 29, 30]. When learning about a systems phenomenon, a systems thinker recursively applies systems thinking rules to change, eliminate or create new constructs until an internally consistent construct is reached as the conclusion to the particular investigation [20]. The application of these rules helps people to understand how the system works and how people interact with the system more effectively and efficiently. The rules include questioning the system boundary; system structure (parts, hierarchy, and whole); interrelationships within the system; interdisciplinary points of view; system processes; holism and big picture thinking.

Educators play a central role in the dissemination of this concept to students [20]. However, the challenge in articulating systems thinking is connected to the prevailing reductionist approach in education that is dominant in the Western world. This approach emphasizes knowledge of the parts and the relationships of those parts rather than the broader interdisciplinary relationships [23]. Currently, in engineering and SE education, as in other education fields, reductionism is usually emphasized for events, parts and isolated processes in contrast to a system paradigm. A large proportion of the teaching effort focuses on teaching specific technologies of the particular field of engineering or specific principles of SE, for example requirements engineering.

SE relies on systems thinking to provide the methods and willingness to view the engineered system at the level of a whole system. Systems thinking serves as a bridge between theory and practice, and between the abstract, intellectual domains and concrete, practical domains. The increasing complexity of engineered products and systems demands that engineering educators develop the capacity of their students for systems thinking, so that the students know and are able to apply the methods for viewing the proposed system from a systems perspective.

The challenge in articulating systems thinking is also driven by limited research on the pedagogical aspects of the topic, including its measurement $[20,23]$. An instrument which can provide a way to measure the transformation of a student's ability in systems thinking, especially in the affective domain, will be of great value to systems engineering education.

It is important for systems engineering educators to develop their students in the affective domain in relation to systems thinking so that those students will be characterized by belief in the power of systems thinking to enable them to develop superior engineered products and systems. The importance of affective development of systems thinking is to ensure that students not only become characterized by the use of traditional, reductionist approaches, but also by the use of systems thinking in their approach to engineering activities, even when working under pressure. Systems engineering education emphasizes the cognitive matters of theory and techniques in the expectation that knowledge of how to approach engineering systemically will result in actual performance of engineering from a systemic perspective. The issue in the affective domain is to cause the engineering to value the systemic approach so that they are characterized by choosing to approach engineering problems from a systemic perspective [32].

\section{AFFECTIVE DOMAIN}

Most teaching and assessment in higher education focuses on developing students in the cognitive domain rather than in the affective domain $[32,33]$. This observation is reinforced by discussions in professional society settings or within a project team developing a reference curriculum, and in the reference curricula produced as a result of such projects. Research about education aimed to produce affective domain outcomes is also limited [34]. In part, this neglect arises from the unclear definition of the affective constructs and the underdeveloped assessment practices related to the affective domain, including scale construction [34].

Bloom's taxonomy of educational outcomes was developed to provide a scientific foundation for curriculum design by setting the level of student attainment of learning outcomes in terms of the kind of learning achievement made by students [ 18 , 35]. It divides the learning space into the cognitive, affective and psychomotor domains. The original Bloom's taxonomy team developed only the cognitive and affective domains as hierarchies of learning achievement types. The cognitive domain addresses the development of intellectual abilities and skills related to knowledge of content and various abilities to use that knowledge, whereas, the affective domain deals with emotions, feelings, valuation and characterization of cognitive domain aspects.

The affective dimension is important in facilitating the effective cognitive processes and the internalization of cognitive aspects [36]. Numerous studies in neurosciences, behavioral neuroscience and clinical psychology showed the substantiated role of the affective domain in generating physiological changes which are also indicative of learning [37]. A positive outcome in the affective domain is considered to be an important antecedent to success in the cognitive domain [38].

Many engineering educators correctly regard the cognitive 
domain as concerning the knowledge of the technology of the particular engineering discipline but confound the affective domain with the so-called 'soft skills' required in the engineering workplace [39, 40]. However, our research builds on a different interpretation of the affective domain than that which is common in engineering education, but is supported by Mogk and Goodwin [41]. Our interpretation is natural to Bloom's taxonomy and is used in some other applications of Bloom's taxonomy, such as objectives for elementary school education. At the elementary school level the affective domain is commonly understood to relate to the development of a value system that results in the student being characterized by couth behavior.

In engineering education, the vision of a secular university which is not involved in development of the personal ethical system of the student leads to the position that the university does not have the place of educating the student to take any particular stance in relation to ethics and therefore results in ethics education being education about ethics rather than education in ethical behavior. This position results from the strongly held 'warfare motif' in the relationship of science and religion, and the current concern to avoid apparent bias in relation to minority groups $[42,43]$.

This then results in the two domains of Bloom's taxonomy being interpreted as being about different subject areas of knowledge rather than as different dimensions of the learner in relation to holistic engagement in education. The two educational settings which stand out as the most obvious types of institutions which engage with the affective domain in the manner intended by the Bloom's taxonomy team are theological seminaries [44] and military academies [45], both of which educate their students for occupations in which success depends on holistic integration of the cognitive and affective dimensions of the graduate.

Our research takes up a variant, and we believe Bloom et al.'s intended, interpretation of the affective domain which integrates the view of the education as a holistic activity which can be viewed from the facets of the three dimensions of Bloom's taxonomy, as facets of achievement of the student and, later, graduate, with respect to a single holistic set of learning objectives. As such there is an integration of the learning of the content, the focus of the cognitive domain, and the development of the student, from 'recognized' to become 'characterized' in their professional value system, by the methods and approaches that are implicit in the knowledge learned in the cognitive space. That is, the student becomes 'emerging and becoming' with regard to the content of learning, and is characterized by belief in the value and appropriateness of the application of the knowledge and capabilities developed through the cognitive dimension of their education, thus taking that knowledge, skill and ability as their default manner of engaging with the engineering task at hand. To illustrate our meaning, the typical engineering graduate who seeks objective evidence that can be mathematically analyzed in order to make decisions demonstrates development of the affective characterization by the scientific foundation of engineering teaching.

The affective domain of systems thinking education in a systems engineering education setting concerns the development of the student's professional characterization to prefer to approach engineering tasks using a whole-of-product, or systems, perspective so that the engineering analysis is focused on ensuring the best match of the whole engineered outcome for the purpose for which it is to be developed. It is important to investigate students' systems thinking development from the affective domain perspective so that the depth of that learning can be understood and assessed.

Nguyen and Bosch [22] described systems thinking by four distinct levels based on the iceberg model for thinking which was proposed by Maani and Cavana [46], events or symptoms; patterns of behaviors; systemic structures; and mental models [46]. The first level, events or symptoms are the most visible yet shallowest level of reality, otherwise, the highest level, mental models reflect the deepest and most profound assumptions, norms, and motivations [22]. Events and symptoms, although representing only the 'tip of the iceberg', is the level at which most decisions and interventions occur [22]. This is because events or symptoms are the most visible part of day-to-day reality, which often seem to require immediate attention and action [22]. Patterns, the second level of systems thinking, is where a larger set of events, or data points, are linked to create a 'story' [22]. Whereas, the systemic structures, the next level of systems thinking, reveal how the patterns and components of the system as a whole relate to, and affect, each other [22]. This represents a much deeper level of systems thinking that can show how the interplay of different factors brings about the outcomes we observe [46]. Finally, the deepest level of systems thinking, the mental models, hardly ever comes to the surface. However, it influences why individuals and organizations work the way they do [46]. Mental models reflect the beliefs, values and assumptions that people personally, hold, and underlie the reasons for doing things the way they do, and, in the context of a community, result in the community having a particular culture [46]. These mental models are the fundamental constructs used by people in order to understand and interact with the world, and therefore are held in the affective domain.

It can be said that in the cognitive domain, systems engineers know how to do specific SE tasks and that those tasks implement the tangible aspects of systems thinking, while in the affective domain they are characterized to do those specific tasks, and guided by the concepts of systems thinking, because they value the benefit that those tasks and concepts provide. However, because the application of a systems thinking mindset creates a dilemma, in a work context, that usually favors tangible and rapid visible progress towards a solution, systems engineers may be challenged to justify the time and effort required by systems thinking. The challenge arises because the outcomes based on systems thinking appear to take additional time and effort to manifest themselves and, therefore, are in tension with the pressure that usually exists to show tangible progress towards a solution to a need at a rate proportionate with the elapse of time spent or, other resources consumed, in the conduct of the engineering work. 


\section{METHODS}

In the work reported here we have developed a questionnaire intended to measure the capacity for and characterization by systems thinking in undergraduate systems engineering students. We also report statistical analysis of the questionnaire responses of a pilot group representative of the target audience in order to test the validity of the questionnaire.

\section{A. Questionnaire Development}

In developing this instrument we found that the interest inventory for assessing Capacity of Engineering Systems Thinking (CEST) introduced by Frank [47] is concerned with the affective domain conceptualized somewhat similarly as we described above. It could be used to distinguish individual engineers based on their characterization for approaching matters using systems thinking.

Frank's instrument was tested and implemented in his first study which aimed at examining its reliability and validity [48]. This study included 54 participants from a large hi-tech organization. The result of this study suggested that the instrument is suitable for assessing systems engineers' feeling and interest towards systems thinking. Frank's second study aimed at strengthening the results of the first study and involved 78 participants [47]. Again, the instrument's reliability and validity were examined. The study revealed the underlying structure of the instrument which includes five factors: seeing the big picture; implementing managerial considerations; using interdisciplinary knowledge for conceptualizing the solution; analyzing the needs and requirements, and; being a systems thinker. Furthermore, a third study [47] was conducted by applying the instrument to the evaluation of the effectiveness of CEST development programs for 153 participants. The result of this study provided additional confirmation for the instrument's validity in assessing the systems engineers' feelings, interest and personal valuation of systems thinking concepts.

However, Frank's instrument was developed for use by professional engineers with some work experience. We adapted the items in Frank's instrument to a context appropriate to undergraduate engineering students. Moreover, Frank's instrument only covered parts of our proposed systems thinking concept which need to be applied when engaging with an engineering system. We created a new instrument by adding items that address other important systems thinking topics including system boundary, system structure, interrelationships and the whole systems engineering processes [20, 21, 49]. About $60 \%$ of the questions in the new 30 items questionnaire were adapted from Frank's CEST instrument, while the remaining items are new inclusions.

TABLE I

THE QUESTIONS PRESENTED IN THE SURVEY

\begin{tabular}{ll}
\hline \hline No & Question Text \\
\hline \hline 1 & $\begin{array}{l}\text { I prefer to deal with the systems aspects rather than the technical } \\
\text { details. }\end{array}$
\end{tabular}

2 When I encounter a problem I first try to find a quick answer without getting involved in the details.

3 When I encounter a problem I like to use multiple viewpoints to understand and analyze it.

4 I believe that the system character can only be seen when the system is together in the assembly of its parts and their interaction.

5 I think I am good at personal project skill and personal organization skills.

$6 \quad$ I prefer leading teams rather than concentrating on my technical job.

7 I like to be bold and take risks.

8 I prefer to ask questions of my colleagues or other students rather than to search for the answers on my own.

9 I enjoy using models, mind maps, rich pictures, causal loop diagrams or graphs to understand problems.

10 I want to advance in both the managerial and technical engineering tracks when I work.

11 It is important to me to acquire knowledge in engineering fields other than my main field of study (e.g. Electrical/Mechanical/etc. Engineering.)

12 It is important for me to learn from the differences between the expected and actual outcomes of action and change my action to improve results.

13 I like to understand the whole system structure including the system entities, their relationships, the system hierarchy and boundary.

14 It is important for me to identify the benefit derived from the combination of elements and actions of the system.

15 When I work in a group project (assignment) I like to see how the parts for which I am responsible function as a part of whole project rather than to concentrate only on my tasks.

16 When I work in a group project (assignment) I value the contributions that the other students contribute to completing the whole task.

17 When I contribute to a group project (assignment) I always look at the interconnections and mutual influences between the main tasks and the peripheral task and how my part interacts with and contributes to the whole task.

18 When I contribute to a group project (assignment) I like to be proactive rather than just accept what has been decided by others.

19 When I contribute to a group project (assignment) I work hard to maintain communication with others involved.

20 When I contribute to a group project (assignment) I prefer to test the available alternative solutions and then recommend the best choice rather than to let others choose the preferred alternative.

21 When I contribute to a group project (assignment) I think continuously about what can be improved rather than concentrating on my goal alone.

22 When I contribute to a group project (assignment) I enjoy reviewing the whole and giving feedback to my group.

23 I see dealing with trade-off considerations (an exchange of one thing in return for another) as part of my engineering role.

24 I believe that I will enjoy finding out and analyzing the customer or market need for a system and 'translating' the needs into technical specifications for products or systems.

25 I am interested in the activities of others who contribute other discipline of knowledge in system development projects.

26 I am interested to know how the product or system I am working will function in practice.

27 I am interested in knowing how the final product or system produced by a project will be supported and maintained.

28 I believe that I will enjoy participating in strategic planning that decides future directions.

29 If I need to make any change in a part or process for which I am responsible I will check the engineering and non-engineering consequences of the change.

30 In my opinion an engineering design should take into account internal organizational and external political, economic and social considerations in addition to technical considerations.

Our reworking of the questionnaire is designed to provide a seven point Likert scale for each item rather than a dichotomous 
rating scale as in Frank's original instrument. There are several reasons for this change. Firstly, dichotomous items can force respondents to choose imprecisely among limited options which may produce a bias because respondents are forced to select an 'extreme' answer that may or may not reflect their true feelings [50]. Secondly, a dichotomous rating scale cannot capture answers that may be located between the two extreme categories, with no chance for expressing an intermediate viewpoint. Thirdly, Preston suggests that rating scales with the fewest response categories yielded the least reliable scores, lowest internal consistency and lowest indices of validity (criterion validity), while the most reliable scores, highest internal consistency and highest indices of validity (criterion validity) were derived from scales with between 6 to 10 response categories [51].

The Likert scale is a commonly accepted summated rating scale which provides respondents a series of attitude dimensions and assumes that each item has equal attitudinal value. Therefore, all items were arranged for scoring on a Likert scale, with seven response categories: 'very untrue of me', 'untrue of me', 'somewhat untrue of me', 'neutral', 'somewhat true of me', 'true of me' and 'very true of me'. A seven category rating scale was chosen because this is the lowest odd number of categories, between six and ten, which was recommended by Preston [51]. An odd number of categories is preferred over an even number of categories [52]. If an even number of points was chosen, a respondent might misinterpret one or two centermost numbers as representing the center or neutral category [52].

The items, shown in Table I, describe students' feelings, interests and personal valuation of systems thinking in relation to their experience as engineering students in a systems engineering course context. This instrument is intended to be completed independently by adults aged 18 years of age and older. We judged it essential that the questionnaire be short, and quick to complete, (approximately 10-15 minutes), easy to follow, comprehensible, and containing questions with language suitable for the target group to improve the probability of completion.

\section{B. Reliability and Validity}

Reliability of an instrument concerns the ability of the instrument to measure consistently and reproducibly, when the same subject is tested under identical conditions. It has two main forms: repeated measurement and internal consistency. We calculated the reliability of the scale using Cronbach's alpha coefficient. Cronbach's alpha, one of the internal consistency measures, has become the common method to estimate the reliability of instruments, especially multipoint data instruments, such as attitude scales with seven response options [53]. To create the instrument with high reliability, the items provided in the instrument need to be clear and unambiguous. A slight ambiguity in the wording of items can affect the reliability of an instrument as a respondent may interpret the items differently at different times [54].

Another essential characteristic of an instrument is validity, the extent to which the instrument measures what it is intended to measure. Content and face validity are judged based on the logical link between the items and the objectives of the instrument [54]. An extensive search of the literature on the concept that is intended to be measured will help to achieve content validity [55]. Meanwhile, asking respondents or experts whether the instrument looks valid to them is a way to achieve face validity [55]. However, the judgment is based on subjective logic, different people may have different opinions; hence, no definite conclusion can be drawn [54]. Therefore, another form of validity needs to be tested, construct validity.

Construct validity is a more sophisticated technique for establishing the validity of an instrument [54]. It is related to the theoretical knowledge of the construct which wants to be measured. It was examined through Exploratory Factor Analysis (EFA) using Principal Component Analysis (PCA) and Confirmatory Factor Analysis (CFA) using Structural Equation Modeling (SEM), respectively.

EFA is often used in the early stages of research to gather information about the interrelationship among items. It was chosen to do EFA first, since it was not hypothesized, in the beginning of study, that the construct had multiple subscales. PCA, one of commonly accepted EFA techniques, was used because it can provide a better empirical summary of a dataset compared with Factor Analysis (FA), another widely accepted EFA technique [56].

CFA was conducted later to test the hypothesis concerning the structure underlying the construct, after it was hypothesized that the construct has a certain number of dimensions as concluded from the EFA process. SEM was used because of its ability to assess the relationships comprehensively and provide a transition from exploratory to confirmatory analysis [57].

\section{Population and Sample}

Target Population. The target population of this study is students enrolled in a systems engineering course in an undergraduate program. The students are recruited from a variety of universities, with a view to enabling comparative analysis of results from the use of the questionnaire in the data collection phase of the project for which it has been developed.

Sample. The sample used for this validation study comprised 180 students from undergraduate systems engineering courses in four universities in four countries: Australia, Indonesia, Singapore and US.

\section{Administration Procedure}

A paper-based questionnaire was distributed to the participants in Australia. Those in Indonesia, Singapore and US were asked to participate in an online implementation of the same questionnaire, implemented in Survey Monkey. All participants were provided with an information sheet about the purpose and possible benefits of the project. The information sheet informed them that participation is voluntary and not linked to their course result. They were encouraged to participate out of altruistic motivation.

Responses from the paper-based questionnaire were recorded using Microsoft Excel for Windows 2007 and exported into SPSS. These results were combined with responses in Survey Monkey exported to SPSS. We used the statistical analysis 
package SPSS for Windows version Statistics 21 and AMOS 21 for the analysis.

TABLE II

DEMOGRAPHIC INFORMATION ABOUT PARTICIPANTS

\begin{tabular}{|c|c|c|}
\hline Characteristic & Number & Percentage \\
\hline $\begin{array}{l}\text { Male gender } \\
\text { Female gender } \\
\text { Average age }\end{array}$ & $\begin{array}{c}139 \\
41 \\
25.6 \text { years }\end{array}$ & $\begin{array}{l}77 \% \\
23 \%\end{array}$ \\
\hline $\begin{array}{l}\text { Australia } \\
\text { Indonesia } \\
\text { Singapore } \\
\text { US }\end{array}$ & $\begin{array}{l}26 \\
52 \\
50 \\
52\end{array}$ & $\begin{array}{l}14 \% \\
29 \% \\
28 \% \\
29 \%\end{array}$ \\
\hline $\begin{array}{l}\text { Part-time students } \\
\text { Full-time students }\end{array}$ & $\begin{array}{l}81 \\
99\end{array}$ & $\begin{array}{l}45 \% \\
55 \%\end{array}$ \\
\hline $\begin{array}{l}\text { Part-time employed } \\
\text { Full-time employed } \\
\text { Not employed }\end{array}$ & $\begin{array}{l}38 \\
83 \\
59\end{array}$ & $\begin{array}{l}21 \% \\
46 \% \\
33 \%\end{array}$ \\
\hline
\end{tabular}

\section{RESULTS AND DISCUSSION}

\section{A. Sample Demographic}

Of the respondents $(n=180), 77 \%$ were male, $23 \%$ were female with an average age of 25.6 years. The distribution of participants was $26(14 \%)$ students from Australia, $50(28 \%)$ students from Singapore, $52(29 \%)$ students from the US and $52(29 \%)$ from Indonesia. Participants indicated that $45 \%$ of them were part time students while the rest were full time students. Moreover, $21 \%$ of participants work part time, $46 \%$ work full time and the remaining participants were not working, Table II.

\section{B. Missing Data Analysis}

Prior to commencing data analysis, a missing data review (an analysis of questions for which no answer was given by participants), was conducted by examining the patterns of missing data and implementing a remedy. To decide whether a remedy for missing data can be applied, the degree of randomness present in the missing data must first be ascertained [57]. Only if the missing data can be classified as missing completely at random (MCAR), can remedies, including replacement of missing data (for missing data which is classified as MCAR) be employed [57].

Little has provided a statistical test of the MCAR assumption using a chi-square test [58]. A significant value indicates that the data are not MCAR [58]. This test was conducted in the SPSS Missing Values Analysis (MVA). Since no significant difference was found (chi-square $=153.536, \mathrm{df}=144$, $\mathrm{sig}=0.278$ ), the missing data can be classified as MCAR. Therefore, missing data remedies can be applied.

Mean substitution is one of the acceptable methods of generating replacement values for the missing data [57]. The rationale of this method is that the mean is the best single replacement value [57]. Missing values for a variable in this dataset were addressed by substituting with the mean value of that variable based on all valid responses. This resulted in a total of six missing values replaced in a matrix $180 \times 30(=5,400)$ data items. The total number of replaced missing values was therefore $0.11 \%$ of the total dataset.
TABLE III

BASIC DESCRIPTIVE OF SAMPLE FOR THE INSTRUMENT

\begin{tabular}{|c|c|c|c|c|c|c|}
\hline Items & Min & Max & Mean & $\begin{array}{c}\text { Std. } \\
\text { Deviation }\end{array}$ & $\begin{array}{c}\text { Skew- } \\
\text { ness }\end{array}$ & $\begin{array}{c}\text { Kurto- } \\
\text { sis }\end{array}$ \\
\hline 1 & 1.00 & 7.00 & 4.711 & 1.396 & -0.555 & -0.262 \\
\hline 2 & 1.00 & 7.00 & 4.038 & 1.604 & -0.023 & -0.987 \\
\hline 3 & 1.00 & 7.00 & 5.516 & 1.140 & $-1,000$ & 1.269 \\
\hline 4 & 1.00 & 7.00 & 4.910 & 1.411 & -0.646 & -0.155 \\
\hline 5 & 1.00 & 7.00 & 5.305 & 1.255 & -0.801 & 0.748 \\
\hline 6 & 1.00 & 7.00 & 4.700 & 1.538 & -0.369 & -0.742 \\
\hline 7 & 1.00 & 7.00 & 4.944 & 1.385 & -0.434 & -0.408 \\
\hline 8 & 1.00 & 7.00 & 4.245 & 1.537 & -0.244 & -0.605 \\
\hline 9 & 1.00 & 7.00 & 4.933 & 1.440 & -0.472 & -0.429 \\
\hline 10 & 1.00 & 7.00 & 5.777 & 1.189 & -1.274 & 2.235 \\
\hline 11 & 2.00 & 7.00 & 5.377 & 1.168 & -0.583 & 0.019 \\
\hline 12 & 1.00 & 7.00 & 5.566 & 0.997 & -0.715 & 1.373 \\
\hline 13 & 1.00 & 7.00 & 5.433 & 1.186 & -0.772 & 0.743 \\
\hline 14 & 1.00 & 7.00 & 5.461 & 1.053 & -0.983 & 2.474 \\
\hline 15 & 1.00 & 7.00 & 5.555 & 1.149 & -1.098 & 1.559 \\
\hline 16 & 1.00 & 7.00 & 5.900 & 1.036 & -1.290 & 2.946 \\
\hline 17 & 2.00 & 7.00 & 5.511 & 1.070 & -0.831 & 0.910 \\
\hline 18 & 2.00 & 7.00 & 5.533 & 1.115 & -0.731 & 0.524 \\
\hline 19 & 2.00 & 7.00 & 5.711 & 0.988 & -1.041 & 2.048 \\
\hline 20 & 1.00 & 7.00 & 5.261 & 1.183 & -0.500 & 0.096 \\
\hline 21 & 3.00 & 7.00 & 5.394 & 1.085 & -0.255 & -0.620 \\
\hline 22 & 2.00 & 7.00 & 5.355 & 1.160 & -0.532 & 0.040 \\
\hline 23 & 2.00 & 7.00 & 5.366 & 1.103 & -0.616 & 0.187 \\
\hline 24 & 1.00 & 7.00 & 5.200 & 1.207 & -0.507 & 0.398 \\
\hline 25 & 1.00 & 7.00 & 5.486 & 1.154 & -0.857 & 0.622 \\
\hline 26 & 1.00 & 7.00 & 5.893 & 1.022 & -1.340 & 3.222 \\
\hline 27 & 1.00 & 7.00 & 5.627 & 1.123 & -1.255 & 2.636 \\
\hline 28 & 1.00 & 7.00 & 5.655 & 1.130 & -0.933 & 1.695 \\
\hline 29 & 2.00 & 7.00 & 5.461 & 1.105 & -0.465 & -0.378 \\
\hline 30 & 1.00 & 7.00 & 5.616 & 1.125 & -0.652 & 0.416 \\
\hline $\begin{array}{c}\text { Average } \\
\text { Score } \\
(\mathrm{N}=180)\end{array}$ & 2.13 & 7.00 & 5.315 & 0.634 & -0.720 & 2.498 \\
\hline
\end{tabular}

\section{Basic Descriptive Statistics}

Table III provides a summary of basic descriptive statistics of 180 respondents' scores on the thirty items of the questionnaire. For thirty items, scores range from a minimum score of 1 (very low) to a maximum score of 7 (very high). The mean of items range from 4.038 (neutral) to 5.9 (positive attitude). Whereas, the average for 180 respondents' scores range from 2.13 to 7.00 with a mean of 5.315. Overall, it can be concluded that the participants have valued systems thinking aspects in their experience as developing engineers by showing a positive attitude to the application of systems thinking.

\section{Reliability and Validity}

A questionnaire with a low alpha coefficient indicates that the item questions are not internally consistent with the rest of the test. The Cronbach's alpha obtained in this study is 0.908 . It indicates excellent internal consistency [59], that is, the interrelatedness of the items in this questionnaire is high.

The content validity of our survey is supported by the fact that the items are based on an extensive literature review of issues related to students' affective learning about systems thinking in systems engineering including Frank's interest inventory for assessing CEST [47]. This review of literature provides content validity because the content in the questionnaire are represented by major scholars in the area of work. Face validity, tested by a short post-questionnaire interview with eight adults representative of the population to be sampled indicated that the questionnaire is quick to complete 
( $<20$ minutes), easy to follow and comprehensible. Some grammatical changes to the questionnaire were conducted after these interviews. Construct validity, which indicates the extent to which the tool measures a theoretical construct, is examined through the EFA and CFA processes explained below.

\section{E. Exploratory Factor Analysis (EFA)}

Prior to commencing PCA, the suitability of the data for the 30 items of the scale for factor analysis was assessed by examining the correlation matrix. Inspection of the inter-item correlation matrix revealed that 316 of 435 correlations or $73 \%$ are significant at the 0.01 level. Furthermore, 217 of 435 correlations present a coefficient of 0.3 or greater than $50 \%$. This provides an adequate basis for proceeding to the next process.

However, some inter-item correlations have negative values, which is potentially incorrect because all items are positive attitude items and, therefore, all inter-item correlations should be positive. It was decided to exclude three items (items 2, 4 and 8) which have negative inter-item correlation as this would increase the alpha coefficient by removing them prior to conducting the next process, the Kaiser-Meyer-Olkin Measure of Sampling Adequacy and Bartlett's Test of Sphericity.

The Kaiser-Meyer-Olkin value was 0.891, exceeding the recommended value of $0.6[60,61]$ and Bartlett's Test of Sphericity (chi-square value $=2321.12, \mathrm{df}=435$, significance of $\mathrm{p}<0.001$ ) reached statistical significance, supporting the factorability of the correlation matrix [62]. It provides an adequate basis for proceeding to the next process, PCA.

Initial analysis of PCA factor extraction was run to obtain eigenvalues for each component in the data. Items with crossloadings $>0.4$ were excluded one at a time, and the factor analysis repeated with the goal of achieving a simple structure in which each item loaded onto a single factor at $>0.4$. This criterion was consistent with accepted values [63].

Five factors emerge from the analysis using the Kaiser criterion, which retain all the components with an eigenvalue exceeding 1. An inspection of the scree plot revealed the inflexions that would justify retaining five components. To aid the interpretation of these five components, orthogonal (Varimax) rotation was performed. The rotated solution revealed the presence of a simple structure, with five components showing a number of strong loadings and all variables loading substantially on only one component.

Table IV shows the simple structure that was achieved after the exclusion of five items (items 7, 10, 15, 26 and 30) that either loaded onto no factor, or cross-loaded at $>0.4$ and were therefore considered to be factorial impure. The eigenvalues and common variance shown in Table IV satisfy typical criteria for a meaningful and interpretable simple structure. These criteria include a minimum of three items in each factor and that the majority of items in the structure have loadings rated as either 'very good' or 'excellent' $(>0.7$ excellent; $>0.63$ very good; $>0.55$ good; $>0.45$ fair) [64].

Therefore, the final version of the questionnaire comprises 22 items which were distributed across five factors, Table V. Overall, the EFA results were supported by the theoretical framework underlying the development of the scale [20, 21, 24, 47]. This instrument could be used to measure students' learning of systems thinking concepts and application in engineering, in the affective domain.

Cronbach's alpha coefficients were calculated for the five subscales. The coefficient alphas for the five subscales were 0.85 for Factor 1, 0.77 for Factor 2, 0.73 for Factor 3, 0.76 for Factor 4 and 0.65 for Factor 5. Although, the alpha coefficient of Factor 5 is a little weak, however, all these values were well within the acceptable range for an exploratory study [57].

TABLE IV

SUMMARY OF EXPLORATORY FACTOR ANALYSIS RESULTS, QUESTION NUMBERS ARE AS DEFINED IN TABLE I

\begin{tabular}{cccccc}
\hline \hline \multirow{2}{*}{ Question Number } & \multicolumn{5}{c}{ Rotated Factor Loadings } \\
\cline { 2 - 6 } & 1 & 2 & 3 & 4 & 5 \\
\hline 24 & $\mathbf{0 . 6 8}$ & 0.33 & -0.01 & -0.01 & 0.34 \\
28 & $\mathbf{0 . 6 5}$ & 0.16 & 0.26 & 0.17 & 0.35 \\
23 & $\mathbf{0 . 6 5}$ & -0.12 & 0.07 & 0.33 & 0.13 \\
27 & $\mathbf{0 . 6 4}$ & 0.18 & 0.15 & 0.26 & 0.03 \\
11 & $\mathbf{0 . 6 4}$ & 0.16 & 0.09 & -0.03 & -0.04 \\
29 & $\mathbf{0 . 5 0}$ & 0.35 & 0.33 & 0.16 & 0.21 \\
3 & $\mathbf{0 . 4 2}$ & 0.20 & 0.34 & 0.22 & 0.23 \\
25 & $\mathbf{0 . 4 2}$ & 0.34 & 0.37 & 0.25 & 0.24 \\
20 & 0.15 & $\mathbf{0 . 7 2}$ & 0.21 & -0.03 & 0.02 \\
21 & 0.14 & $\mathbf{0 . 7 1}$ & 0.37 & 0.14 & 0.10 \\
18 & 0.12 & $\mathbf{0 . 6 5}$ & 0.01 & 0.35 & 0.21 \\
22 & 0.35 & $\mathbf{0 . 6 1}$ & 0.14 & 0.24 & 0.05 \\
9 & 0.06 & 0.08 & $\mathbf{0 . 7 9}$ & 0.02 & 0.12 \\
14 & 0.20 & 0.23 & $\mathbf{0 . 6 7}$ & 0.29 & 0.05 \\
13 & 0.28 & 0.33 & $\mathbf{0 . 6 4}$ & 0.21 & 0.04 \\
16 & 0.21 & 0.01 & 0.30 & $\mathbf{0 . 8 1}$ & 0.02 \\
19 & 0.07 & 0.39 & -0.02 & $\mathbf{0 . 6 7}$ & 0.18 \\
17 & 0.30 & 0.25 & 0.29 & $\mathbf{0 . 5 3}$ & 0.15 \\
12 & 0.39 & 0.28 & 0.35 & $\mathbf{0 . 4 1}$ & 0.06 \\
6 & 0.21 & 0.15 & -0.15 & 0.17 & $\mathbf{0 . 7 3}$ \\
1 & 0.16 & -0.01 & 0.17 & -0.08 & $\mathbf{0 . 7 3}$ \\
5 & 0.02 & 0.13 & 0.23 & 0.20 & $\mathbf{0 . 7 1}$ \\
\hline \hline Alpha coefficient & 0.85 & 0.77 & 0.73 & 0.76 & 0.65 \\
\hline
\end{tabular}

TABLE V

DISTRIBUTION OF ITEMS INTO FIVE FACTORS BASED ON EFA

\begin{tabular}{|c|c|c|}
\hline Factor & Items & Description \\
\hline 1 & $\begin{array}{l}24,28,23,17 \\
11,29,3,25\end{array}$ & $\begin{array}{l}\text { Students' valuation of interdisciplinary and } \\
\text { SE processes }\end{array}$ \\
\hline 2 & $20,21,18,22$ & Students' valuation of teamwork \\
\hline 3 & $9,14,13$ & $\begin{array}{l}\text { Students' valuation of understanding of } \\
\text { systems structure, hierarchy and boundaries }\end{array}$ \\
\hline 4 & $16,19,17,12$ & $\begin{array}{l}\text { Students' valuation of understanding } \\
\text { relationships }\end{array}$ \\
\hline 5 & $6,1,5$ & $\begin{array}{l}\text { Students' valuation of managerial skill and } \\
\text { big picture thinking }\end{array}$ \\
\hline
\end{tabular}

\section{F. Confirmatory Factor Analysis (CFA)}

The most direct method of validating the factor structure resulting from EFA is to move to a confirmatory perspective and assess the replicability of the results, either with a split sample in the original data set or with a separate sample [57]. In the present study, the original data set was used again in a CFA using SEM in AMOS 11 software package. SEM plays a confirmatory role because the researcher has complete control over the specification of indicators for each construct and allows for a statistical test of the fit indices for the proposed 
confirmatory solution, which is not possible with EFA methods, including PCA or FA [57]. This technique was applied to confirm the multidimensional structure which is five factors structure that resulted from previous EFA by comparing this structure with other competing structures.

TABLE VI

SUMMARY OF CFA RESULTS

\begin{tabular}{ccccccc}
\hline \hline Model & $\begin{array}{c}\text { Global } \\
\text { factor }\end{array}$ & $\begin{array}{c}\text { Two } \\
\text { factors }\end{array}$ & $\begin{array}{c}\text { Three } \\
\text { factors }\end{array}$ & $\begin{array}{c}\text { Four } \\
\text { factors }\end{array}$ & $\begin{array}{c}\text { Five factor } \\
\text { orthogonal }\end{array}$ & $\begin{array}{c}\text { Five } \\
\text { factor } \\
\text { oblique }\end{array}$ \\
\hline$\chi^{2}$ & 877.756 & 457.240 & 411.640 & 373.922 & 267.981 & 334.525 \\
df & 405 & 208 & 2.6 & 203 & 193 & 214 \\
$\mathrm{p}$ & 0.000 & 0.000 & 0.000 & 0.000 & 0.000 & 0.000 \\
GFI & 0.741 & 0.806 & 0.822 & 0.837 & 0.880 & 0.865 \\
RMSEA & 0.081 & 0.082 & 0.075 & 0.069 & 0.047 & 0.051 \\
TLI & 0.751 & 0.811 & 0.842 & 0.867 & 0.939 & 0.913 \\
CFI & 0.768 & 0.830 & 0.860 & 0.883 & 0.949 & 0.927 \\
AGFI & 0.702 & 0.746 & 0.782 & 0.796 & 0.843 & 0.826 \\
$\chi^{2} / \mathrm{df}$ & 2.167 & 2.198 & 1.998 & 1.842 & 1.389 & 1.563 \\
\hline \hline
\end{tabular}

A CFA was then conducted by comparing the five factor orthogonal model derived from the EFA process with five alternative models, which are a one factor model, a two factor model, a three factor model, a four factor model and a five factor oblique model. The two factor model consists of a combination of factors 1 and 2 resulted from previous EFA and a combination of factors 3,4 and 5 . The three factor model was built from factor 1, combined factors 2 and 3, and combined factors 4 and 5 . The four factor model comprises factors 1, 2, 3 and combined factors 4 and 5 . While the five factor oblique model is a five factor model which underlies the 22 items that emerged by employing PCA with oblique rotation. Numerical results are shown in Table VI.

Absolute fit, incremental fit and parsimonious fit measures were used in this analysis. Absolute fit measures determine the degree to which the overall model predicts the observed covariance and correlation matrix [57]. The incremental fit measures compares the proposed model to some baseline model, most often referred to as the null model [57]. A null model in which all the observed variables are uncorrelated is the most commonly used baseline model [65]. Parsimonious fit measures relate the goodness-of-fit of the model to the number of estimated coefficients required to achieve the level of fit [57].

Among the absolute fit measures commonly used to evaluate SEM are the likelihood ratio chi-square $\left(\chi^{2}\right)$ statistic, the goodness-of-fit statistic and the root mean square error approximation. The Tucker-Lewis Index (TLI) and comparative fit index (CFI) are measures which are commonly used when assessing incremental fit of the model compared with a null model. The adjusted goodness-of-fit index (AGFI) and the normed chi-square are used to assess the parsimony of the proposed model by evaluating the fit of the model versus the number of estimated coefficients, or conversely, the degrees of freedom, needed to achieve the level of fit [57].

In referring to this table, it can be observed that the likelihood chi-square $\left(\chi^{2}\right)$ statistics for all three competing models were significant $(\mathrm{p}<0.001)$. Taken alone these results would suggest an unsatisfactory fit to the data for all competing models. However, the chi-square statistic is quite sensitive, in different ways, to both small and large sample sizes, and this measure should be complemented with other measures of fit [57]. More significantly, the other measures indicated that the five factor orthogonal model which resulted from EFA had the greatest degree of fit when compared with the one factor model, the two factor model, the three factor model, the four factor model and the five factor oblique model. The five factor orthogonal model had the best fit because:

1. It had the highest goodness-of-fit (GFI: 0.880). Although no absolute threshold levels for acceptability have been established, higher values indicate better fit [57].

2. It had the lowest root mean square error of approximation (RMSEA: 0.047). It was recommended that values of RMSEA less than 0.05 are considered as indicative of close fit $[66,67]$.

3. It had the highest Tucker-Lewis Index (TLI: 0.939) and comparative fit index (CFI: 0.949) which are more than 0.9 $[57,67]$ and closer to 0.95 [65]

4. It had the highest adjusted goodness-of-fit index value (AGFI: 0.843) which is close to the recommended level of 0.90 [57].

5. It had the lowest normed chi-square $\left(\chi^{2} / \mathrm{df}: 1.388\right)$, which is less than 2 [67], where a large value of chi-square relative to degree of freedom signifies that observed and estimated matrices differ considerably [57]. Combined with AGFI, this result allows conditional support to be given for the model parsimony [57].

The various measures of the absolute fit, incremental fit and parsimonious fit measures indicate that the model is marginally acceptable at best of intended five construct. These measures support deeming the results an acceptable representation of the hypothesized construct of the factor structure which is derived from the EFA process. This analysis helps to validate the construct of scale.

\section{CONCLUSION}

It is important for engineering educators, especially SE educators, to develop students' learning of systems thinking in the affective domain, so that the students will be characterized by belief in the power of systems thinking to enable them to develop superior engineered products or systems. Further, they not only know how to do specific systems engineering tasks which employ systems thinking, but also they are characterized to do those specific tasks by embedding systems thinking concepts and preference for their use.

This paper is the first study to report the psychometric properties of an instrument that would examine the extent of students' learning in the affective domain in systems thinking in engineering education, especially SE education. The Principal Component Analysis (PCA) factor extraction method used for exploratory factor analysis revealed a previously unknown factor underlying the questionnaire. Moreover, Structural Equation Modeling (SEM) plays a role to confirm the five factor structure that resulted from PCA by comparing this structure with other competing structures.

The outcome is a 22 item multidimensional scale with five factors that represent students' feelings, interests and personal 
valuation, that is, their affective learning, of systems thinking. It demonstrates a fundamental coherence with Frank's CEST instrument [47] and our proposed systems thinking rules. These preliminary data support the reliability and validity of this questionnaire. The results suggest that this instrument is a suitable tool for measurement of students' learning of systems thinking in the affective domain and supports the view that the scale may be useful for further application.

However, each factor is associated with between 3 and 8 questions. This raises the possibility of some redundancy in the questions - e.g. factor 1 indicating potential to review the survey to reduce the number of questions without loss of fidelity. Moreover, because the instrument is newly developed, it is crucial that the researchers continue to test the psychometric properties, including test and retest reliability, an important psychometric property, which is not covered in this study. Further studies are also needed to test the usefulness of this new scale in specific contexts, for example, in research which aims to investigate students' systems thinking development in relation to the affective engagement in courses that aim to promote systems thinking. Students are asked to complete the instrument shortly after the start of a course and again near the end of the course. Any changes to systems thinking can then be reasonably attributed to the course, teaching and learning environment. Another important issue worthy of further investigation is the question of how these test results change over a longer period of time.

\section{REFERENCES}

[1] G. S. Parnell, P. J. Driscoll, and D. L. Henderson, "Introduction to system engineering," in Decision Making in System Engineering and Management, G. S. Parnell, Ed., 2nd ed New Jersey: John Wiley \& Sons, 2011.

[2] Editorial Board BKCASE. (2014, 29 January 2015). The Guide to the Systems Engineering Body of Knowledge (SEBoK). Available: www.sebokwiki.org

[3] R. S. Kalawsky, "Grand challenges for systems engineering research," in 7th Annual Conference on Systems Engineering Research, 2009, pp. 20 23.

[4] A. F. Squires and R. J. Cloutier, "Comparing percepetions of competency knowledge development in systems engineering curriculum: A case study," presented at the 118th ASEE Annual Conference and Exposition, Vancouver, BC, Canada, 2011.

[5] A. F. Squires, "Investigating the relationship between online pedagogy and student perceived learning of systems engineering competencies," Doctor of Philosophy Dissertasion, Stevens Institute of Technology, Hoboken, NJ 07030, 2011.

[6] D. Gonçalves, "Developing systems engineers," in Portland International Conference on Management of Engineering \& Technology (PICMET) 2008, pp. 1963-1972.

[7] Department of Defence, "Building Defence Capability: a Policy for a Smarter and More Agile Defence Industry Base," D. o. Defence, Ed., ed 2010

[8] A. Pyster, D. H. Olwell, T. L. J. Ferris, N. Hutchison, S. Enck, J. Anthony, et al. (2012, 29 January 2015). Graduate Reference Curriculum for Systems Engineering (GRCSE®). Available: www.bkcase.org/grcse/

[9] C. M. T. Lamb, "Collaborative Systems Thinking: An exploration of the mechanisms enabling team systems thinking," Doctor of Philosophy, Department of Aeronautics and Astronautics, Massachusetts Institute of Technology, 2009.

[10] P. Godfrey, "How systems thinking contribute to systems engineering," ed: INCOSE UK, 2010.

[11] T. L. J. Ferris, "Comparison of systems engineering competency frameworks," presented at the 4th Asia-Pasific Conference on Systems engineering (APCOSE 2011), Keelung, Taiwan, 2010.
[12] S. Witjes, P. M. Specht, and C. M. Rodriguez, "The measurement of the development of systems and general thinking in agricultural areas of Colombia; preliminary results," in 50th Annual Meeting of the ISSS, 2006.

[13] C. Foster, M. Crowder, K. Nelson, and T. Ganesh, "Work in progress: Developing engineering systems thinking through the modeling of a complex bioengineering system," in Frontiers in Education Conference (FIE), 2012, 2012, pp. 1-2.

[14] J. K. Doyle, M. J. Radzicki, and W. S. Trees, "Measuring change in mental models of complex dynamic systems," in Complex Decision Making, ed: Springer, 2008, pp. 269-294.

[15] L. B. Sweeney and J. D. Sterman, "Bathtub dynamics: initial results of a systems thinking inventory," System Dynamics Review, vol. 16, pp. 249$286,2000$.

[16] K. Y. H. Connell, S. M. Remington, and C. M. Armstrong, "Assessing systems thinking skills in two undergraduate sustainability courses: a comparison of teaching strategies," Journal of Sustainability Education, vol. 3, 2012.

[17] W. Hung, "Enhancing systems-thinking skills with modelling," British Journal of Educational Technology, vol. 39, pp. 1099-1120, 2008.

[18] B. S. Bloom, M. D. Engelhart, E. J. Furst, W. H. Hill, and D. R. Krathwohl, Taxonomy of Educational Objectives the Classification of Educational Goals Handbook I: Cognitive Domain. London: Longman Group Ltd., 1956.

[19] O. J. H. Bosch, C. A. King, J. L. Herbohn, I. W. Russell, and C. S. Smith, "Getting the big picture in natural resource management-systems thinking as 'method'for scientists, policy makers and other stakeholders," Systems Research and Behavioral Science, vol. 24, pp. 217-232, 2007.

[20] D. Cabrera, "Systems thinking," Doctor of Philosophy Dissertation, Faculty of the Graduate School of Cornell University, Cornell University, 2006.

[21] D. Cabrera, L. Colosi, and C. Lobdell, "Systems thinking," Evaluation and Program Planning, vol. 31, pp. 299-310, 2008.

[22] N. C. Nguyen and O. J. H. Bosch, "A systems thinking approach to identify leverage points for sustainability: a case study in the Cat Ba Biosphere Reserve, Vietnam," Systems Research and Behavioral Science, vol. 30, pp. 104-115, 2013

[23] N. C. Nguyen, D. Graham, H. Ross, K. Maani, and O. Bosch, "Educating systems thinking for sustainability: experience with a developing country," Systems Research and Behavioral Science, vol. 29, pp. 14-29, 2012.

[24] H. L. Davidz, "Enabling systems thinking to accelerate the development of senior systems engineers," Doctor of Philosophy, Engineering Systems Division, Massachusetts Institute of Technology, 2006.

[25] P. H. Werhane, "Moral imagination and systems thinking," Journal of Business Ethics, vol. 38, pp. 33-42, 2002.

[26] B. Richmond, "Systems thinking/system dynamics: Let's just get on with it," System Dynamics Review, vol. 10, pp. 135-157, 1994.

[27] P. A. Walker, R. Greiner, D. McDonald, and V. Lyne, "The Tourism Futures Simulator: a systems thinking approach," Environmental Modelling and Software, vol. 14, pp. 59-67, 1998.

[28] K. T. Yeo, "Systems thinking and project management - time to reunite," International Journal of Project Management, vol. 11, pp. 111-117, 1993.

[29] M. Kapsali, "Systems thinking in innovation project management: A match that works," International Journal of Project Management, vol. 29, pp. 396-407, 2011.

[30] M. Kunc, "Using systems thinking to enhance strategy maps," Management Decision, vol. 46, pp. 761-778, 2008.

[31] J. B. Atwater and P. H. Pittman, "Facilitating systemic thinking in business classes," Decision Sciences Journal of Innovative Education, vol. 4, pp. 273-292, 2006

[32] J. Hanus, S. Hamilton, and J. S. Russel, "The cognitive and affective domain in assessing the life-learning objectives," American Society for Engineeering Education, 2008.

[33] K. Shephard, "Higher education for sustainability: seeking affective learning outcomes," International Journal of Sustainability in Higher Education, vol. 9, pp. 87-98, 2008.

[34] Y. S. Rivera, "Promoting motivation through mode of instruction: the relationship between use of affective teaching tachniques and motivation to learn science," Doctor of Education, Lehigh University, 2010.

[35] D. R. Krathwohl, B. S. Bloom, and B. B. Masia, Taxonomy of Educational Objectives the Classification of Educational Goals Handbook II: Affective Domain: David McKay Company, Inc., 1964.

[36] T. A. Lashari, M. Alias, Z. A. Akasah, and M. J. Kesot, "An affective cognitive teaching and learning framework in engineering education," ASEAN Journal of Engineering Education, vol. 1, pp. 11-24, 2012. 
[37] W. Zhang and J. Lu, "The practice of affective teaching: A view from brain science," International Journal of Psychological Studies, vol. 1, pp. 35-41, 2009.

[38] A. Boyle, S. Maguire, A. Martin, C. Milsom, R. Nash, S. Rawlinson, et al., "Fieldwork is good: The student perception and the affective domain," Journal of Geography in Higher Education, vol. 31, pp. 299-317, 2007.

[39] P.-K. Lin, P.-C. Lin, and S.-Y. Li, "Workplace competencies in demand: Perception gaps between service industries and manufacturing industries," in 9th International Conference on Service Systems and Service Management (ICSSSM), Shanghai, China, 2012, pp. 639-642.

[40] M. Barnes, M. Bailey, P. R. Green, and D. A. Foster, "Teaching embedded microprocessor systems by enquiry-based group learning," International Journal of Electrical Engineering Education, vol. 43, pp. 1-14, 2006.

[41] D. W. Mogk and C. Goodwin, "Learning in the field: Synthesis of research on thinking and learning in the geosciences," Geological Society of America Special Papers, pp. 131-163, 2012.

[42] J. H. Evans and M. S. Evans, "Religion and science: Beyond the epistemological conflict narrative," Annual Review of Sociology vol. 34, pp. $87-105,2008$

[43] G. A. Boysen, D. L. Vogel, M. A. Cope, and A. Hubbard, "Incidents of bias in college classrooms: Instructor and student perceptions," Journal of Diversity in Higher Education, vol. 2 pp. 219-231, 2009.

[44] M. Dowson and D. M. McInerney, "For what should theological colleges educate? A systematic investigation of ministry education perceptions and priorities," Review of Religious Research, vol. 46 pp. 403-421, 2005

[45] S. T. Hannah and B. J. Avolio, "Moral potency: Building the capacity for character-based leadership," Consulting Psychology Journal, vol. 62, pp. 291-310, 2010

[46] K. E. Maani and R. Y. Cavana, Systems Thinking, Systems DynamicsManaging Change and Complexity, 2nd ed. New Zealand: Pearson Education New Zealand, 2007.

[47] M. Frank, "Assesing interest for systems engineering positions' required capacity for engineering systems thinking (CEST)," Systems Engineering, vol. 13,pp. 161-174, 2010.

[48] M. Frank, O. Zwikael, and M. Boasson, "Jobs requiring a capacity for engineering systems thinking (CEST): Selection using an interest inventory," Project Management vol. 38, pp. 36-44, 2007.

[49] H. L. Davidz, D. J. Nightingale, and D. H. Rhodes, "Accelerating the development of senior systems engineers," in The 15th Annual International Symposium INCOSE 2005, pp. 10-15.

[50] B. C. K. Choi and A. W. P. Pak, "A catalog of biases in questionnaire," Preventing Chronic Disease, Public Health Research, Practice and Policy, vol. 2, pp. 1-13, 2005.

[51] C. C. Preston and A. M. Colman, "Optimal number of response categories in rating scales: reliability, validity, discriminating power, and respondent preferences," Acta Psychologica, vol. 104, pp. 1-15, 2000.

[52] B. Johnson and L. Christensen, Educational Research: Quantitative, Qulitative, and Mixed Approaches, 4th ed. California, USA: SAGE Publications, 2012.

[53] W. Wiersma and S. G. Jurs, Research Methods in Education: An Introduction, 9th ed. Boston: Pearson, 2009.

[54] R. Kumar, Research Methodology: A Step-by-Step Guide for Beginner, 3rd ed. London: SAGE Publications, 2011.

[55] D. Muijs, Doing Quantitative Research in education with SPSS, 1st ed. London: SAGE Publications, 2004.

[56] J. Pallant, SPSS Survival Manual: A Step-by-Step Guide to Data Analysing using SPSS. Sydney: Allen \& Unwin, 2007.

[57] J. F. Hair, R. E. Anderson, R. L. Tatham, and W. C. Black, Multivariate Data Analysis, 4th ed. ed. New York: Prentice-Hall, 1998

[58] D. C. Howell, "The treatment of missing data," The Sage handbook of social science methodology, pp. 208-224, 2007.

[59] D. George and P. Mallery, SPSS for Windows Step by Step: a Simple Guide and Reference, 14.0 update ed. Bacon, Boston: Pearon/Allyn, 2007.

[60] H. Kaiser, "A second generation Little Jiffy," Psychometrika, vol. 35, pp. 401-415, 1970.

[61] H. Kaiser, "An index of factorial simplicity," Psychometrika, vol. 36, pp. 31-36, 1974.

[62] M. S. Bartlett, "A note on the multiplying factors for various chi square approximations," Journal of the Royal Statistical Society, vol. 16 (series B), pp. 296-298, 1954.

[63] D. H. Cropley, J. C. Kaufman, and A. J. Cropley, "Measuring creativity for innovation management," Journal of Technology Management \& Innovation, vol. 6, pp. 13-30, 2011.
[64] A. L. Comrey and H. B. Lee, A First Course in Factor Analysis 2nd ed. Hillsdale, NJ: Lawrence Erlbaum, 1992.

[65] L. Hu and P. Bentler, "Cutoff criteria for fit indexes in covariance structure analysis: Conventional criteria versus new alternatives," Structural Equation Modeling: A Multidisciplinary Journal, vol. 6, pp. 1$55,1999$.

[66] M. W. Browne and R. Cudeck, "Alternative ways of assessing model fit," Sociological Methods \& Research, vol. 21, pp. 230-258, 1992.

[67] H. W. Marsh and K. T. Hau, "Assessing goodness of fit: Is patrimony always desirable?," Journal of Experimental Education, vol. 64, p. 364, Summer 1996.

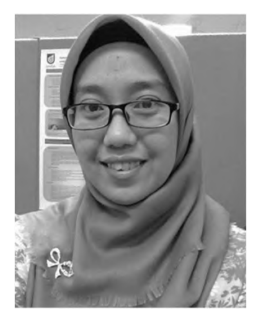

Fanny Camelia received the degrees B.Eng (Industrial), Andalas University, Indonesia in 2003 and M.AppPrjMgmt (Defence), the University of Adelaide, Adelaide, SA in 2011. She is currently working toward the Ph.D. degree in systems engineering at the School of Engineering, University of South Australia, Mawson Lakes, Australia.

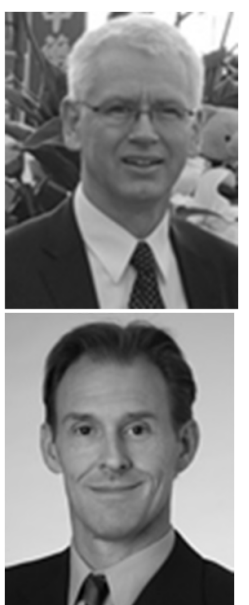

Timothy L.J. Ferris (M'91-SM'02) holds the degrees B.E.Hons, B.Th., B.Litt.Hons., GradCertEd, and PhD, University of South Australia. He worked as an Engineer for the Electricity Trust of South Australia before becoming a faculty member in University of South Australia, at Mawson Lakes, South Australia, in 1991. By the time of publication of this paper, he will be a member of faculty at Cranfield University, UK. Dr Ferris is a member of INCOSE. He is an Associate Editor of IEEE Systems Journal.

David Cropley received degrees B.S, Salford University, UK, in 1989 and PhD, University of South Australia, Adelaide, SA in 1997. His $\mathrm{PhD}$ was in the area of measurement systems engineering. He is a lecturer in the School of Engineering at the University of South Australia, and his primary areas of research creativity and innovation in engineering. 